\title{
O SOFRIMENTO MORAL EM PROFISSIONAIS DE ENFERMAGEM NA ONCOLOGIA: ESTUDO COM MÉTODO MISTO
}

\author{
Maiara Rodrigues dos Santos \\ Ana Paula Neroni Stina Saura \\ Izabel Alves das Chagas Valóta \\ Ana Lúcia Siqueira Costa
}

Introdução: O fenômeno do sofrimento moral (SM) vêm sendo explorado constantemente na literatura, desde a definição de Jameton(1). Foi definido como sentimentos negativos advindos quando não se pode agir de acordo com uma resposta moralmente correta para uma situação, por limitações institucionais e hierárquicas. Diante da contínua exposição dos profissionais de enfermagem às respostas psicológicas mal adaptativas no cuidado, atrelado a uma literatura frágil na análise do sofrimento moral no contexto da oncologia, propõe-se este estudo com o objetivo de compreender a ocorrência do sofrimento moral (SM) em profissionais de enfermagem na oncologia.

Método: Este estudo utilizará o modelo sequencial explanatório da abordagem de métodos misto(2), composto por duas fases em sequência: a primeira quantitativa e, posteriormente, a fase qualitativa. Na primeira fase, hipóteses quantitativas versam sobre a associação do sofrimento moral com características dos profissionais de enfermagem no contexto da oncologia, bem como, com consequências para a saúde do trabalhador como desfecho. Para tanto, um estudo observacional prospectivo será realizado visando conhecer as correlações entre o SM e o perfil biossocial, ocupacional e de saúde do profissional de enfermagem de um hospital especializado em oncologia. Será utilizada a Escala de Sofrimento Moral(3), o Inventário Malash de Burnout e a Lista de Sintomas de Stress. A fase qualitativa acontecerá em sequência com o objetivo de elucidar resultados obtidos na primeira fase quantitativa e de ajudar explicar de forma mais ampla o fenômeno. Serão conduzidos grupos focais e entrevistas semiestruturadas fundamentadas pelo Interacionismo Simbólico e Teoria Fundamentada nos Dados(4) (TFD). Serão critérios de inclusão: (1) ser profissional da área da enfermagem, (2) trabalhar na instituição há pelo menos 6 meses. A análise dos dados de questionários utilizará o teste de correlação de Pearson para verificar a correlação entre o sofrimento moral e características biossociais, ocupacionais e de saúde. Na fase qualitativa, a amostragem será intencional mediante análise prévia dos dados quantitativos, que definirão os setores e/ou participantes a serem convidados para participar da coleta dos dados. A análise desses dados ocorrerá mediante transcrição, leitura e re-leitura dos dados, codificação e categorização para formação de

temas. Este projeto foi submetido ao Comitê de Ética em Pesquisa da EEUSP e aguarda parecer.

Resultados esperados: O resultado de um estudo de método misto consiste na integração dos dados da fase quantitativa e qualitativa para a compreensão do fenômeno estudado. O produto de análise dos resultados deste estudo será um modelo teórico formal sobre o sofrimento moral em profissionais de enfermagem na oncologia. Esperase com os resultados deste estudo, fortalecer evidencias sobre a ocorrência de sofrimento moral e suas consequências para a saúde do trabalhador em oncologia. 
Conclusões: Por meio de uma análise em profundidade que este estudo propõe sobre a ocorrência do sofrimento moral, almeja-se tecer contribuições para a prática por meio do delineamento de estratégias de prevenção das reações psicossociais mal adaptativas geradas pelo estresse no cotidiano do trabalho, otimizando custos das instituições de saúde e garantindo a qualidade do cuidado e segurança do paciente com câncer e de sua família. 